\title{
The impact of bone mineral density and disc degeneration on shear strength and stiffness of the lumbar spine following laminectomy
}

\author{
Arno Bisschop - Margriet G. Mullender • Idsart Kingma • \\ Timothy U. Jiya $\cdot$ Albert J. van der Veen · Jan C. Roos • \\ Jaap H. van Dieën • Barend J. van Royen
}

Received: 25 February 2011/Revised: 1 June 2011 / Accepted: 31 July 2011 / Published online: 24 August 2011

(C) The Author(s) 2011. This article is published with open access at Springerlink.com

\begin{abstract}
Purpose Laminectomy is a standard surgical procedure for elderly patients with symptomatic degenerative lumbar stenosis. The procedure aims at decompression of the affected nerves, but it also causes a reduction of spinal shear strength and shear stiffness. The magnitude of this reduction and the influence of bone mineral density (BMD) and disc degeneration are unknown. We studied the influence of laminectomy, BMD, and disc degeneration on shear force to failure (SFF) and shear stiffness (SS).

Methods Ten human cadaveric lumbar spines were obtained (mean age 72.1 years, range 53-89 years). Laminectomy was performed either on L2 or L4, equally divided within the group of ten spines. BMD was assessed by dual X-ray absorptiometry (DXA). Low BMD was defined as a BMD value below the median. Intervertebral
\end{abstract}

A. Bisschop - M. G. Mullender - T. U. Jiya .

B. J. van Royen $(\bowtie)$

Department of Orthopedic Surgery, Research Institute MOVE,

VU University Medical Center, De Boelelaan 1117,

P.O. Box 7057, $1081 \mathrm{HV}$ Amsterdam, The Netherlands

e-mail: bj.vanroyen@vumc.nl

I. Kingma $\cdot$ J. H. van Dieën

Research Institute MOVE, Faculty of Human Movement

Sciences, VU University Amsterdam, Van der Boechorststraat 7,

1081 BT Amsterdam, The Netherlands

A. J. van der Veen

Department of Physics and Medical Technology,

VU University Medical Center, De Boelelaan 1118,

1081 HV Amsterdam, The Netherlands

J. C. Roos

Department of Radiology, VU University Medical Center,

De Boelelaan 1117, 1081 HV Amsterdam, The Netherlands discs were assessed for degeneration by MRI (Pfirmann) and scaled in mild and severe degeneration groups. Motion segments L2-L3 and L4-L5 were isolated from each spine. SFF and SS were measured, while loading simultaneously with 1,600 $\mathrm{N}$ axial compression.

Results Low BMD had a significant negative effect on SFF. In addition, a significant interaction between low BMD and laminectomy was found. In the high BMD group, SFF was 2,482 N (range 1,678-3,284) and decreased to $1,371 \mathrm{~N}$ (range 940-1,886) after laminectomy. In the low BMD group, SFF was $1,339 \mathrm{~N}$ (range 909-1,628) and decreased to $761 \mathrm{~N}$ (range 561-1,221). Disc degeneration did not affect SFF, nor did it interact with laminectomy. Neither low BMD nor the interaction of low BMD and laminectomy did affect SS. Degeneration and its interaction with laminectomy did not significantly affect SS.

Conclusions In conclusion, low BMD significantly decreased SFF before and after lumbar laminectomy. Therefore, DXA assessment may be an important asset to preoperative screening. Lumbar disc degeneration did not affect shear properties of lumbar segments before or after laminectomy.

Keywords Laminectomy - Human lumbar spine · Shear strength - Shear stiffness - Bone mineral density . Disc degeneration

\section{Introduction}

Symptomatic degenerative spinal stenosis is the most common indication for lumbar surgery in patients over 65 years of age [21]. Symptoms include leg, back and buttock pain, radiculopathy, neurogenic claudication and 
subjective muscle weakness. The standard surgical procedure for symptomatic degenerative lumbar spinal stenosis is decompression of the spinal canal by laminectomy [7]. Despite preservation of the facet joints, the anatomical integrity and stabilizing function of bony structures, and interspinous, supraspinous and flavum ligaments is lost. Most complications reported after laminectomy are related to postoperative segmental instability of the lumbar spine or postoperative spondylolisthesis [8]. The increased occurrence of postoperative fractures of the pars interarticularis following laminectomy might result from a reduced resistance to shear forces [15].

Both in vitro and finite element studies have shown that the shear stiffness of the spinal segment after laminectomy, whether or not combined with other decompression techniques, is reduced $[11,20]$. In addition, laminectomy as well as removal of posterior elements substantially reduces spinal strength in shear loading $[11,19,20]$. In vitro experiments have also shown that shear loading can lead to bony failure of the posterior elements of the spine, with fracturing of the pars interarticularis most often reported [1]. Therefore, it is quite likely that decreased resistance to shear loading after laminectomy plays a crucial role in the incidence of postoperative complications, i.e. the so-called post-laminectomy syndrome.

The relation between laminectomy combined with partial facetectomy and the reduction of shear force to failure (SFF) have recently been studied in healthy young porcine spines. The relative SFF reduction was quite limited (22\%). The shear stiffness (SS) of these spinal segments was reduced by $9 \%$ after treatment [20].

However, it has been shown that a normal, healthy disc substantially contributes to shear resistance [19]. In contrast to young porcine spines, the spines of patients with degenerative lumbar stenosis often show signs of intervertebral disc degeneration. In addition, it has been shown that degenerative changes in the intervertebral disc affect the mechanical properties of the lumbar motion segment [13]. Yet, the interaction between the effects of laminectomy and disc degeneration of the lumbar spine has not been studied. Furthermore, it is well known that low bone mass affects the risk of vertebral fracture [17]. Hence, low bone mineral density (BMD) potentially could reduce SFF and SS and may interact with laminectomy as well.

In the present study, we quantified the effects of laminectomy on the SFF and SS in ten human cadaveric lumbar spines. We also assessed the relation of these biomechanical features with BMD and disc degeneration. We hypothesized that laminectomy substantially reduces SFF and SS of the human lumbar spine, and that BMD and disc degeneration influence the residual SFF and SS after laminectomy.

\section{Methods}

Specimens and specimen preparation

Thoracolumbar spines (T12-L5) were harvested from freshly frozen $\left(-20^{\circ} \mathrm{C}\right)$ human cadavers (mean age 72.1 years, range 53-89 years). None of the deceased subjects had any history of spinal injury, spinal surgery or spinal metastatic disease. The spines were thawed before testing. Excessive soft tissue and muscle tissue were carefully removed, keeping the anterior and posterior longitudinal ligaments as well as the facet joints intact. Laminectomy was performed at level L2 of five randomly chosen thoracolumbar spines, and at level L4 of the remaining five thoracolumbar spines. The untreated level of each thoracolumbar spine was considered as internal control. Since correlations between mechanical properties of segments from the same spine are considered high, the adjacent segment from the same spine was used as control. To exclude systematic effects of segment level, laminectomy was performed randomly at L2 or L4. Laminectomy, analogous to standard clinical practice, was performed by removing the spinous process and part of the lamina. During preparation, assessment and biomechanical testing, specimens were kept hydrated using $0.9 \%$ saline-soaked gauzes. Furthermore, anteroposterior, lateral and oblique radiographs were made to determine whether bridging osteophytes were present in segments. Thoracolumbar spines with bridging osteophytes were excluded from this study.

Before testing, BMD $\left(\mathrm{g} / \mathrm{cm}^{2}\right)$ of each lumbar spinal section (L1-L4) was measured with dual X-ray absorptiometry (DXA, Hologic @ QDR 4500 Delphi DXA scanner, Waltham, MA, USA) in anteroposterior direction. Low BMD was defined as lower than median, while high BMD was defined as median or higher. Dichotomized BMD was related as an independent variable to biomechanical outcomes in a generalized estimating equations (GEE) model.

MRI (Siemens@ $@$ Symphony 1.5 T: Syngo MR A30, software NUMARIS/4, Berlin, Germany) of T12-L5 segments was performed to assess disc degeneration. Degeneration of intervertebral discs was graded according to the Pfirrmann classification for lumbar spinal degeneration [14]. Grading was performed on T2-weighted midsagittal sections. Subsequently, degeneration scores were dichotomized; grades 3 or lower were classified as 'mildly degenerated', while grades higher than 3 were classified as 'severely degenerated'. Dichotomized disc degeneration was related as an independent variable to biomechanical outcomes in a GEE model.

Subsequently, each spinal segment (T12-L5) was dissected into two motion segments (L2-L3 and L4-L5). The motion segments were potted in a casting mold using low melting point $\left(48^{\circ} \mathrm{C}\right)$ bismuth alloy (Cerrolow-147; $48 \%$ 
bismuth, $25.6 \%$ lead, $12 \%$ tin, $9.6 \%$ cadmium, and $4 \%$ indium). The disc was placed parallel based on visual inspection to the flat surface of the bismuth. The upper and lower vertebral bodies were fixed securely into the alloy by adding screws into the vertebral body. Screw fixation was reinforced with orthopedic bone cement (Stryker@ ${ }^{\circ}$, Simplex, Kalamazoo, MI, USA). All articulating parts were kept free.

\section{Biomechanical testing procedure}

The casting mold was placed in a hydraulic materials testing machine (Instron $\odot$, model 8872; Instron and IST, Norwood, Canada) (Fig. 1). The caudal vertebral body was fixed on a plateau that allowed movement in axial and transverse directions only. Transverse movements were allowed, so segments were able to find their physiological motion patterns and to correct for possible differences in embedding. Segments were loaded with an axial compressive force of 1,600 N [19]. A pure axial compressive force was applied using a pneumatic cylinder. Calibration of axial compression was performed using a load cell (Hottinger Baldwin Messtechnik, Force Transducer Type C2, Darmstadt, Germany). Since compression was applied in a purely axial direction, bending moments were minimized. The chosen amount of preload was selected to allow

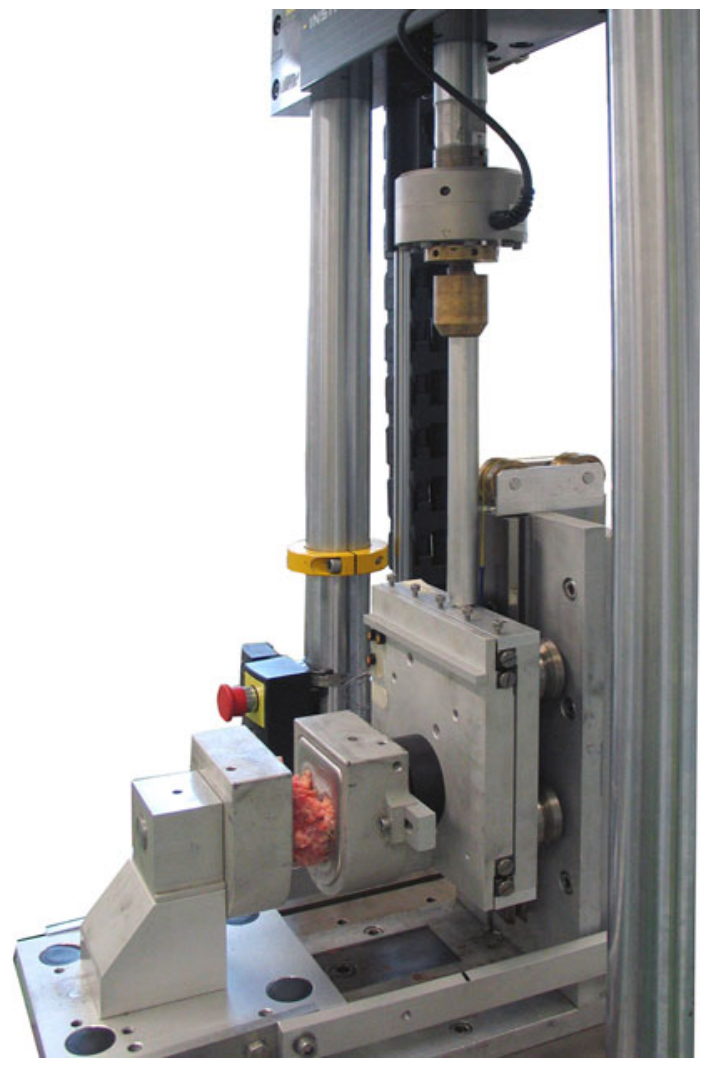

Fig. 1 Segment placed in the materials testing machine for comparison with previous work [19]. Subsequently, anterior shear load was applied with a constant rate of $2.0 \mathrm{~mm} / \mathrm{min}$ on the casting mold containing the cranial vertebral body, until failure of the vertebral motion segment [20]. The test was stopped after hearing a clear crack or after a large force reduction was seen. Shear force and displacement were digitized and stored at 100 samples per second (Instron@ Fast Track 2, Norwood, Canada).

For each of the 20 motion segments tested, SFF and displacement at the instant of failure (DF) were determined. Failure was defined as the point at which maximum load was recorded in the load-displacement curves (Fig. 2) for each specimen. The SFF was defined as the maximum force in Newton until failure. The average SS was calculated from the load-displacement curve. SS was calculated between 25 and $75 \%$ of the SFF. SS was estimated by means of a least squares fit of a straight line through the shear force-displacement data with the slope of the fitted line representing stiffness. The deformation in this region was linear, with an $r^{2}>0.925$ (Table 1) between load and displacement for all motion segments.

\section{Statistical methods}

Generalized estimating equations (GEE) were used to assess relationships between dependent and independent variables. The GEE is a regression analysis that takes the repeated measures character of the data into account. Dependent variables were SFF, DF and SS. First, analyses were performed to determine the effect of laminectomy on all three dependent variables with correction for the confounding effect of segment level. Segment level was added to the GEE model as a dichotomous independent variable. Next, we tested whether dichotomized BMD and disc degeneration

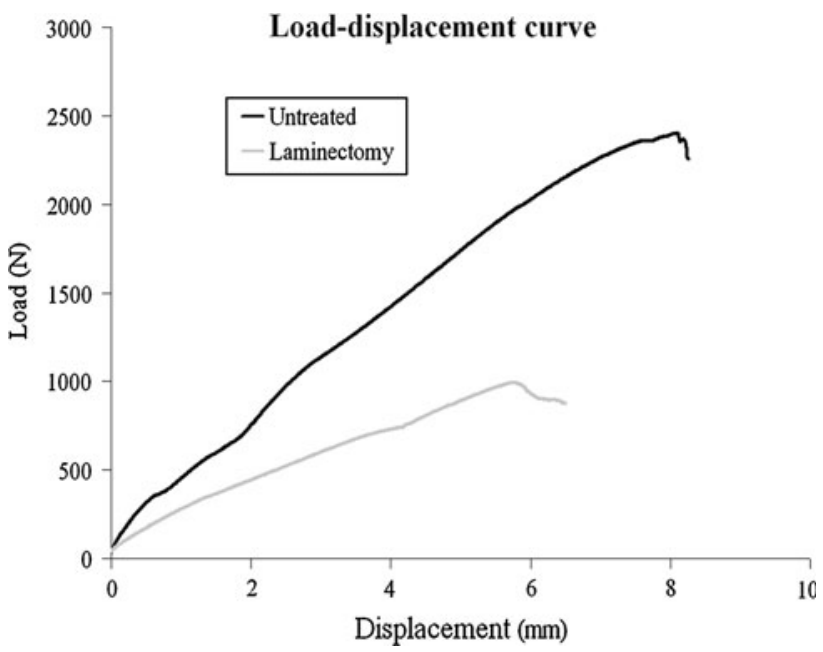

Fig. 2 Load-displacement curve of two motion segments from one human cadaver. In this case segment L2-L3 was with laminectomy, while L4-L5 was untreated 
Table 1 Specimens; independent and dependent variables per segment

\begin{tabular}{|c|c|c|c|c|c|c|c|}
\hline & \multirow[t]{2}{*}{ Segment } & \multicolumn{3}{|c|}{ Independent variables } & \multicolumn{3}{|c|}{ Dependent variables } \\
\hline & & $\begin{array}{l}\text { Laminectomy } \\
(0 / 1)\end{array}$ & $\begin{array}{l}\text { Total bone mineral } \\
\text { density of L1-L4 } \\
\left(\mathrm{g} / \mathrm{cm}^{2}\right)\end{array}$ & $\begin{array}{l}\text { Disc degeneration } \\
\text { (Pfirrmann) (1-5) }\end{array}$ & $\begin{array}{l}\text { Shear force to } \\
\text { failure }(\mathrm{N})\end{array}$ & $\begin{array}{l}\text { Displacement at } \\
\text { failure }(\mathrm{mm})\end{array}$ & $\begin{array}{l}\text { Shear } \\
\text { stiffness } \\
(\mathrm{N} / \mathrm{mm})\end{array}$ \\
\hline \multirow{2}{*}{$\begin{array}{l}\text { Specimen } 01 \\
\quad(\text { male } 79)\end{array}$} & L2-L3 & 0 & \multirow[t]{2}{*}{0.87} & 4 & 2,317 & 11.2 & $282(0.994)$ \\
\hline & L4-L5 & 1 & & 3 & 1,258 & 7.9 & $164(0.997)$ \\
\hline \multirow{2}{*}{$\begin{array}{l}\text { Specimen } 02 \\
\quad(\text { male } 53)\end{array}$} & L2-L3 & 0 & \multirow[t]{2}{*}{0.89} & 2 & 3,284 & 15.9 & $188(0.998)$ \\
\hline & L4-L5 & 1 & & 3 & 1,886 & 9.4 & $234(0.997)$ \\
\hline \multirow{2}{*}{$\begin{array}{l}\text { Specimen } 03 \\
\text { (male } 72 \text { ) }\end{array}$} & L2-L3 & 0 & \multirow[t]{2}{*}{0.95} & 5 & 1,678 & 9.3 & $147(0.925)$ \\
\hline & L4-L5 & 1 & & 5 & 1,775 & 8.6 & $270(0.996)$ \\
\hline \multirow{2}{*}{$\begin{array}{r}\text { Specimen } 04 \\
\text { (female } 82)\end{array}$} & L2-L3 & 0 & \multirow[t]{2}{*}{0.45} & 4 & 909 & 3.9 & $238(0.995)$ \\
\hline & L4-L5 & 1 & & 5 & 561 & 2.1 & $341(1.000)$ \\
\hline \multirow{2}{*}{$\begin{array}{l}\text { Specimen } 05 \\
\text { (male } 78)\end{array}$} & L2-L3 & 0 & \multirow[t]{2}{*}{0.51} & 4 & 1,292 & 6.8 & $275(0.998)$ \\
\hline & L4-L5 & 1 & & 4 & 1,221 & 7.6 & $212(0.998)$ \\
\hline \multirow{2}{*}{$\begin{array}{l}\text { Specimen } 06 \\
(\text { male, } 79)\end{array}$} & L2-L3 & 1 & \multirow[t]{2}{*}{0.65} & 2 & 994 & 6.3 & $152(0.997)$ \\
\hline & L4-L5 & 0 & & 3 & 2,408 & 9.9 & $323(0.996)$ \\
\hline \multirow{2}{*}{$\begin{array}{l}\text { Specimen } 07 \\
\text { (male 62) }\end{array}$} & L2-L3 & 1 & \multirow[t]{2}{*}{0.91} & 2 & 940 & 5.7 & $191(0.998)$ \\
\hline & L4-L5 & 0 & & 5 & 2,724 & 17.7 & $254(0.998)$ \\
\hline \multirow{2}{*}{$\begin{array}{r}\text { Specimen } 08 \\
\text { (female 64) }\end{array}$} & L2-L3 & 1 & \multirow[t]{2}{*}{0.58} & 3 & 660 & 3.4 & $178(0.993)$ \\
\hline & L4-L5 & 0 & & 3 & 1,553 & 7.5 & $214(0.968)$ \\
\hline \multirow{2}{*}{$\begin{array}{r}\text { Specimen } 09 \\
\text { (female 63) }\end{array}$} & L2-L3 & 1 & \multirow[t]{2}{*}{0.57} & 3 & 641 & 5.7 & $83(0.973)$ \\
\hline & L4-L5 & 0 & & 3 & 1,313 & 5.0 & $332(0.998)$ \\
\hline \multirow{2}{*}{$\begin{array}{l}\text { Specimen } 10 \\
\text { (female } 89)\end{array}$} & L2-L3 & 1 & \multirow[t]{2}{*}{0.59} & 4 & 721 & 3.9 & $192(0.994)$ \\
\hline & L4-L5 & 0 & & 4 & 1,628 & 11.6 & $263(0.994)$ \\
\hline
\end{tabular}

For shear stiffness, $r^{2}$ values are added in brackets

0 untreated, 1 laminectomy

co-determined independent variables and whether these modified the effects of laminectomy, by adding an interaction term to the model, which was omitted when not significant. The same procedure was used for dichotomized Pfirrmann scores. A significance level of 5\% was used. The statistical analyses were performed using SPSS for Mac version 16.0 (SPSS Incorporated $\odot$, Chicago, IL, USA).

\section{Results}

All specimen parameters and outcome measures are presented in Table 1. MRI images and visual inspection confirmed that facet joints were intact and no fractures of the pars interarticularis were present in operated or intact segments before mechanical testing.

The median total BMD of all sections (L1-L4) was $0.62 \mathrm{~g} / \mathrm{cm}^{2}$ (range 0.45-0.95). Therefore, low BMD was defined as $<0.62 \mathrm{~g} / \mathrm{cm}^{2}$ and high BMD as $\geq 0.62 \mathrm{~g} / \mathrm{cm}^{2}$. Ten segments were classified, according to Pfirrmann [14], as mildly degenerated and ten segments as severely degenerated.
All statistical results are presented in Table 2. Laminectomy resulted in a decrease of SFF (44.2\%), DF (38.6\%) and SS (19.9\%), which was significant according to the GEE models with laminectomy and level as independent variables.

Low BMD had a significant negative effect on SFF. In addition, a significant interaction between low BMD and laminectomy was found (Fig. 3; Table 2). In the high BMD group, SFF was 2,482 N (range 1,678-3,284) and decreased to $1,371 \mathrm{~N}$ (range 940-1,886) after laminectomy. In the low BMD group, SFF was $1,339 \mathrm{~N}$ (range 909-1,628) and decreased to $761 \mathrm{~N}$ (range 561-1,221). Disc degeneration based on a Pfirrmann scale did not affect SFF, nor did it interact with laminectomy (Fig. 4; Table 2).

Low BMD also reduced DF. The interaction between low BMD and laminectomy did not reach significance (Fig. 3; Table 2). Disc degeneration was not found to affect DF (Fig. 4; Table 2).

Neither low BMD nor the interaction of low BMD and laminectomy did affect SS (Fig. 3; Table 2). Degeneration and its interaction with laminectomy did not significantly affect SS (Fig. 4; Table 2). 
Table 2 Regression coefficients (corrected for segment level) and $p$ values (in brackets with significant values in bold) for the effects of laminectomy, as well as the effects of bone mineral density (BMD) and disc degeneration and their interactions with laminectomy on shear force to failure (SFF), displacement at failure (DF), and shear stiffness (SS)

\begin{tabular}{|c|c|c|c|c|c|c|}
\hline & Intercept & Laminectomy & $\begin{array}{l}\text { Bone mineral } \\
\text { density }(\mathrm{BMD}) \\
\text { High:0 }\left(\geq 0.62 \mathrm{~g} / \mathrm{cm}^{2}\right) \\
\text { Low: } 1\left(<0.62 \mathrm{~g} / \mathrm{cm}^{2}\right)\end{array}$ & $\begin{array}{l}\text { Bone mineral } \\
\text { density }(\mathrm{BMD}) \\
\text { High:0 }\left(\geq 0.62 \mathrm{~g} / \mathrm{cm}^{2}\right) \\
\text { Low: } 1\left(<0.62 \mathrm{~g} / \mathrm{cm}^{2}\right) \\
\mathrm{x} \\
\text { Laminectomy }\end{array}$ & $\begin{array}{l}\text { Disc degeneration } \\
\text { (Pfirrmann) } \\
\text { Mild: } 0(1-3) \\
\text { Severe: } 1(4,5)\end{array}$ & $\begin{array}{l}\text { Disc degeneration } \\
\text { (Pfirrmann) } \\
\text { Mild: } 0(1-3) \\
\text { Severe: } 1(4,5) \\
\mathrm{x} \\
\text { Laminectomy }\end{array}$ \\
\hline $\mathrm{SFF}(\mathrm{N})$ & $1,895(<\mathbf{0 . 0 0 1})$ & $-1,105$ (0.004) & - & - & - & - \\
\hline SFF (N) & $2,375(<\mathbf{0 . 0 0 1})$ & $-1,271(<\mathbf{0 . 0 0 1})$ & $-1,197(<\mathbf{0 . 0 0 1})$ & $676(<\mathbf{0 . 0 0 1})$ & - & - \\
\hline SFF (N) & $1,569(\mathbf{0 . 0 0 8})$ & $-984(0.114)$ & - & - & 409 (0.138) & $622(0.051)$ \\
\hline $\mathrm{DF}(\mathrm{mm})$ & $9.4(<\mathbf{0 . 0 0 1})$ & $-4.4(\mathbf{0 . 0 1 9})$ & - & - & - & - \\
\hline $\mathrm{DF}(\mathrm{mm})$ & $11.9(<\mathbf{0 . 0 0 1})$ & $-5.3(<\mathbf{0 . 0 0 1})$ & $-6.3(<\mathbf{0 . 0 0 1})$ & $3.3(0.071)$ & - & - \\
\hline $\mathrm{DF}(\mathrm{mm})$ & $5.3(<\mathbf{0 . 0 0 1})$ & $-1.3(0.781)$ & - & - & $5.1(0.081)$ & $-0.6(0.843)$ \\
\hline $\mathrm{SS}(\mathrm{N} / \mathrm{mm})$ & $226(<\mathbf{0 . 0 0 1})$ & $-67(\mathbf{0 . 0 2 2})$ & - & - & - & - \\
\hline $\mathrm{SS}(\mathrm{N} / \mathrm{mm})$ & $219(<\mathbf{0 . 0 0 1})$ & $-71(0.082)$ & $16(0.565)$ & $0(0.996)$ & - & - \\
\hline $\mathrm{SS}(\mathrm{N} / \mathrm{mm})$ & $225(<\mathbf{0 . 0 0 1})$ & $-77(\mathbf{0 . 0 4 0 )}$ & - & - & $2(0.950)$ & $55(0.132)$ \\
\hline
\end{tabular}

Each row in the table represents a regression equation. For example, the second row should be read as: SFF $=2,375-1,271$ (laminectomy: 0 or 1) $-1,197$ (low BMD: 0 or 1 ) +676 (laminectomy: 0 or $1 \times$ low BMD: 0 or 1 )

\section{Discussion}

In this study, we investigated the effects of laminectomy, $\mathrm{BMD}$, and disc degeneration and their interaction on SFF and shear stiffness (SS). The results corroborated our hypothesis that SFF and SS after laminectomy are reduced. In addition, we found that BMD did affect SFF but not SS. In contrast, disc degeneration did not act as a determinant of SFF or SS before or after laminectomy.

Laminectomy was found to reduce SFF of the lumbar spine by approximately 50\%. A low BMD also reduced SFF by half, relative to a high BMD. In addition, we found an interaction between BMD and laminectomy. As the regression coefficients in Table 2 indicate, this interaction implied a smaller absolute, but similar relative effect of laminectomy in segments with low BMD as in segments with a high BMD. In both, SFF was roughly halved by laminectomy, i.e. from approximately 2,400 to $1,100 \mathrm{~N}$ in segments with high BMD and from approximately 1,200 to $500 \mathrm{~N}$ in segments with low BMD (Fig. 4).

Our findings are in line with results reported in other in vitro and finite element studies, which also showed reduced shear strength and stiffness of the spine after laminectomy $[11,19,20]$. However, declines found in the present study (44.2\% for SFF and $19.9 \%$ for SS) were much larger than those found in a similar study using porcine specimens ( $22 \%$ for SFF and $9 \%$ for SS), even though facetectomy was performed in addition to laminectomy in the latter study [20]. With facetectomy, a larger reduction of strength and stiffness could be expected.

Differences in results may be due to differences in species, geometry, age, and degeneration. We hypothesized that especially the latter would affect outcomes. Previous studies observed that the intervertebral disc is responsible for $63-74 \%$ of the ultimate shear strength [20]. Therefore, the quality of the intervertebral disc was thought to be of great influence. However, differences in disc degeneration within the present sample did not affect SFF and SS of the segments. In this study, disc degeneration was included as a dichotomized variable. The present specimens all showed signs of degeneration, possibly resulting in a too small variance in disc degeneration to detect its effect. Due to the limited availability of donor material, the sample size in this study was small. The effect of degeneration on dependent variables may exist but is likely to be relatively small in the range studied (all degenerated). In addition, the studied range of spinal segments is comparable to the range that is clinically relevant. Moreover, in contrast to our expectations degeneration appeared to enhance SFF and SS rather than to reduce it.

Since the effect of laminectomy on ultimate shear strength and shear stiffness is considerable, chances of developing postoperative pars interarticularis fractures and spondylolisthesis after laminectomy seem quite substantial, especially when the patient has low BMD. It may be questioned whether patients can safely perform physically demanding tasks after lumbar laminectomy. In physically demanding tasks such as lifting, lumbar spine shear forces have been estimated to range from 1,000 to $1,770 \mathrm{~N}$ at the L5-S1 joint level [9, 10]. Therefore, our data (mean SFF after laminectomy was 1,066 N) suggest that laminectomy puts a patient at risk of developing a post-laminectomy syndrome when performing demanding activities. The decrease in amplitude of displacement at 


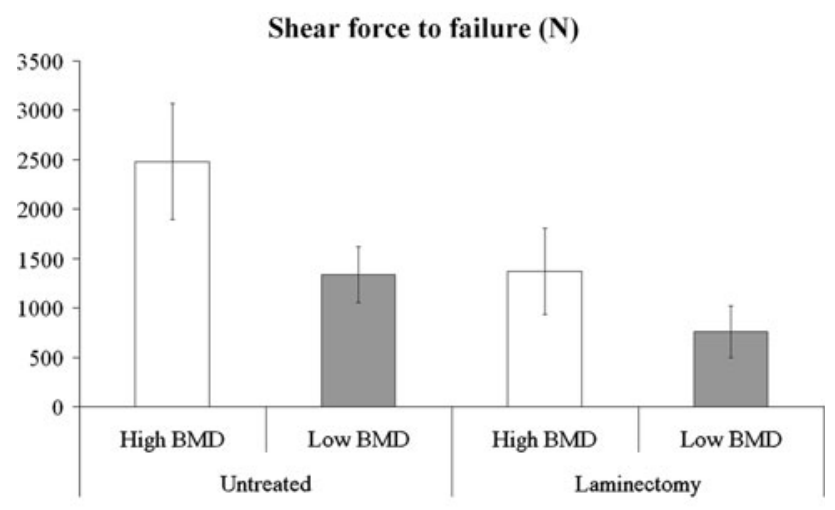

Displacement at failure ( $\mathrm{mm})$
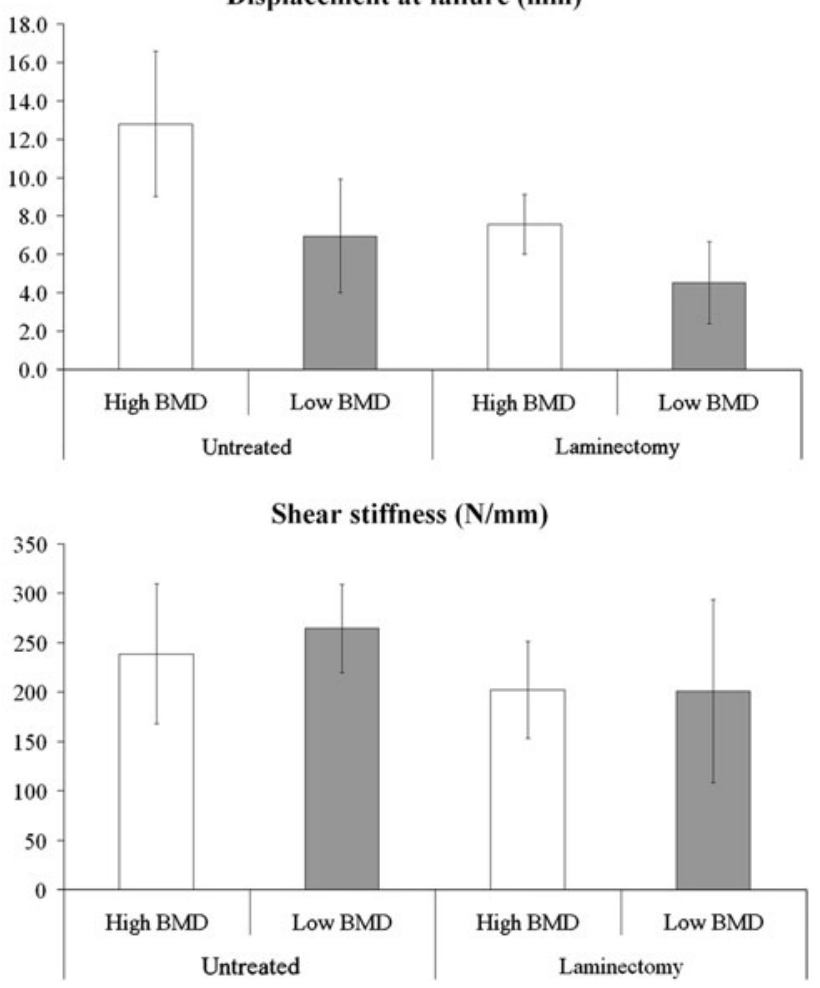

Fig. 3 Shear force to failure (SFF), displacement at failure (DF) and shear stiffness (SS) in relation to BMD and laminectomy (mean values $\pm \mathrm{SD})$, according to GEE modeling

failure after laminectomy also shows that less 'slipping' (i.e. absolute shear displacement) is necessary before trauma occurs.

Standard pre-operative assessment for laminectomy does not include DXA measurement. Our results suggest that knowledge of BMD may be valuable in pre-operative assessment of patients undergoing decompressive surgery. Subjects with low BMD may require additional posterior instrumented stabilization to prevent postoperative instability. In clinical practice, laminectomy is often, but not always, combined with posterior instrumentation and fusion to prevent complications such as spondylolisthesis $[2,5,7]$.
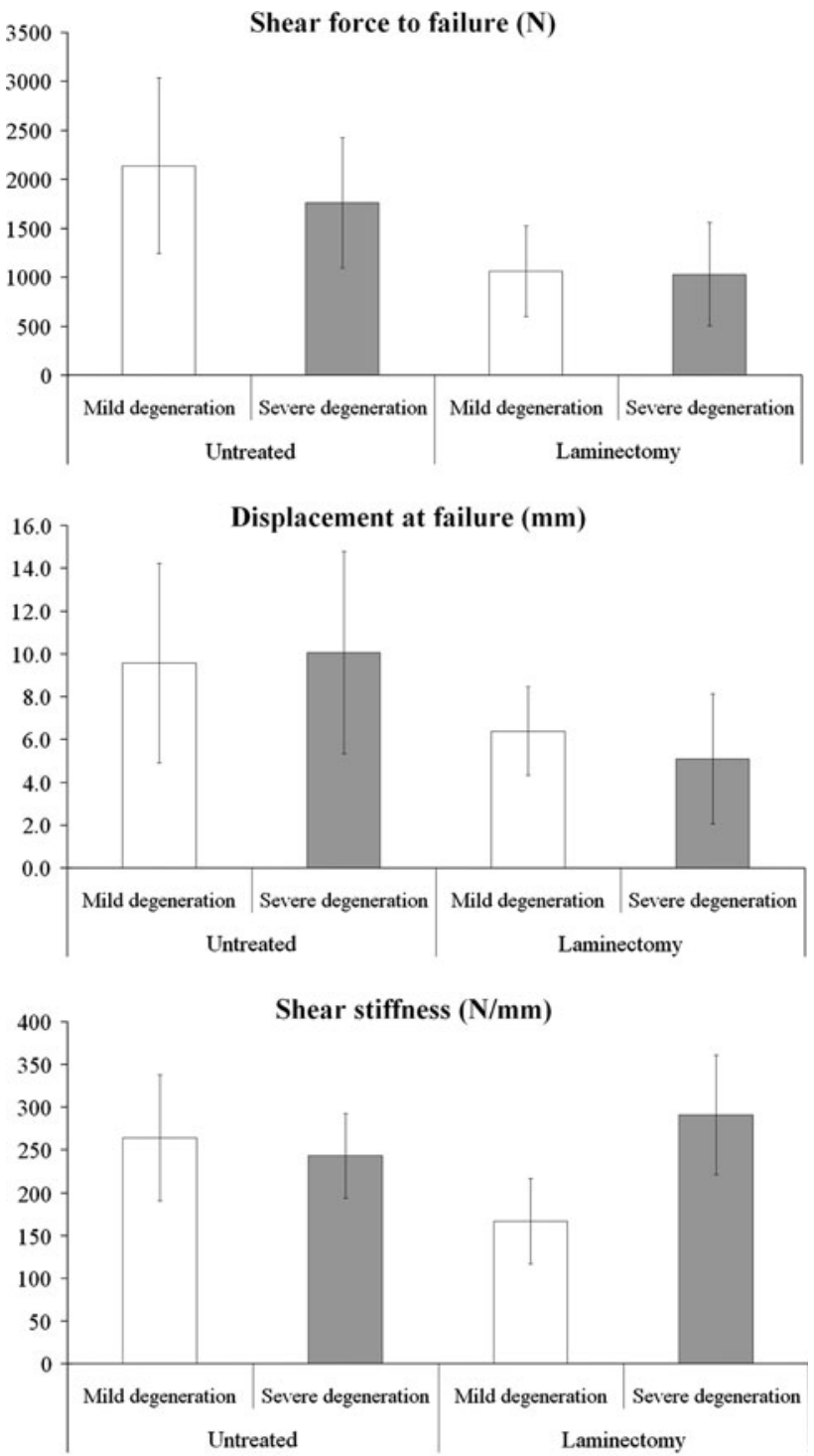

Fig. 4 Shear force to failure (SFF), displacement at failure (DF) and shear stiffness (SS) in relation to disc degeneration and laminectomy (mean values $\pm \mathrm{SD}$ ), according to GEE modeling

The procedure of stabilization itself increases the probability of implant-related complications, including infection, nerve injury, possible adjacent disc degeneration, increased blood loss, extended surgery time, and instrumentation failure [3, 4]. Moreover, it significantly increases the costs of surgery [3]. The probability of implant-related complications needs to be weighted against the risk of postoperative complications after laminectomy without stabilization [12].

It has been shown that axial compression and shear forces are quite strongly correlated across a range of daily activities [18] and axial compression is known to increase the shear stiffness of the intervertebral disc [6, 16]. Therefore, segments were pre-loaded in compression. We 
selected a compression load of $1,600 \mathrm{~N}$ because it is physiologically relevant with the applied shear loads, and allows for comparison with previous work [19].

In the present study, DXA measurement was performed after laminectomy for practical reasons. This leads to a slight underestimation of BMD. However, BMD was measured over the complete lumbar section of L1-L4, and laminectomy was performed on one segment in each spinal segment. Therefore, it is expected that this did not influence the outcomes.

Finally, we used a single loading cycle. Cyclic loading might, through visco-elastic behavior of the intervertebral disc, shift load to the posterior elements [19], thereby possibly enhancing the effect of laminectomy on SFF.

In conclusion, a $44.2 \%$ reduction of SFF and a $19.9 \%$ reduction in SS due to laminectomy were observed in ten fresh frozen elderly human lumbar spines. Low BMD had a significant negative effect on SFF. In addition, a significant interaction between low BMD and laminectomy was found. Disc degeneration did not affect SFF, nor did it interact with laminectomy. Neither low BMD nor the interaction of low BMD and laminectomy did affect SS. Disc degeneration and its interaction with laminectomy did not significantly affect SS.

Acknowledgments No funds were received in support of this work. No benefits in any form have been or will be received from a commercial party related directly or indirectly to the subject of this manuscript. The authors thank Prof. Dr. P. V. J. M. Hoogland, M.D., Ph.D, Dr. R. L. A. W. Bleys, M.D., Ph.D, and Drs. J. F. H. Veldhuizen, M.D. for their contribution.

\section{Conflict of interest None}

Open Access This article is distributed under the terms of the Creative Commons Attribution Noncommercial License which permits any noncommercial use, distribution, and reproduction in any medium, provided the original author(s) and source are credited.

\section{References}

1. Beadon K, Johnston JD, Siggers K, Itshayek E, Cripton PA (2008) A repeatable ex vivo model of spondylolysis and spondylolisthesis. Spine (Phila Pa 1976) 33:2387-2393

2. Christensen FB (2004) Lumbar spinal fusion. Outcome in relation to surgical methods, choice of implant and postoperative rehabilitation. Acta Orthop Scand Suppl 75:2-43

3. Deyo RA, Nachemson A, Mirza SK (2004) Spinal-fusion surgery-the case for restraint. N Engl J Med 350:722-726
4. Ekman P, Moller H, Shalabi A, Yu YX, Hedlund R (2009) A prospective randomised study on the long-term effect of lumbar fusion on adjacent disc degeneration. Eur Spine J 18:1175-1186

5. Fox MW, Onofrio BM (1997) Indications for fusion following decompression for lumbar spinal stenosis. Neurosurg Focus 3:e2

6. Gardner-Morse MG, Stokes IA (2003) Physiological axial compressive preloads increase motion segment stiffness, linearity and hysteresis in all six degrees of freedom for small displacements about the neutral posture. J Orthop Res 21:547-552

7. Hansraj KK, Cammisa FP, Jr, O'Leary PF, Crockett HC, Fras CI, Cohen MS, et al. (2001) Decompressive surgery for typical lumbar spinal stenosis. Clin Orthop Relat Res 384:10-17

8. Herkowitz HN, Kurz LT (1991) Degenerative lumbar spondylolisthesis with spinal stenosis. A prospective study comparing decompression with decompression and intertransverse process arthrodesis. J Bone Joint Surg Am 73:802-808

9. Kingma I, Bosch T, Bruins L, van Dieën JH (2004) Foot positioning instruction, initial vertical load position and lifting technique: effects on low back loading. Ergonomics 47:1365-1385

10. Kingma I, Faber GS, Bakker AJ, van Dieën JH (2006) Can low back loading during lifting be reduced by placing one leg beside the object to be lifted? Phys Ther 86:1091-1105

11. Lee KK, Teo EC (2004) Effects of laminectomy and facetectomy on the stability of the lumbar motion segment. Med Eng Phys 26:183-192

12. Martin CR, Gruszczynski AT, Braunsfurth HA, Fallatah SM, O'Neil J, Wai EK (2007) The surgical management of degenerative lumbar spondylolisthesis: a systematic review. Spine (Phila Pa 1976) 32:1791-17981

13. Nachemson AL, Schultz AB, Berkson MH (1979) Mechanical properties of human lumbar spine motion segments. Influence of age, sex, disc level, and degeneration. Spine (Phila Pa 1976) 4:1-8

14. Pfirrmann CW, Metzdorf A, Zanetti M, Hodler J, Boos N (2001) Magnetic resonance classification of lumbar intervertebral disc degeneration. Spine (Phila Pa 1976) 26:1873-1878

15. Rothman SL, Glenn WV Jr, Kerber CW (1985) Postoperative fractures of lumbar articular facets: occult cause of radiculopathy. AJR Am J Roentgenol 145:779-784

16. Stokes IA, Gardner-Morse M, Churchill D, Laible JP (2002) Measurement of a spinal motion segment stiffness matrix. J Biomech 35:517-521

17. Turner CH (2002) Biomechanics of bone: determinants of skeletal fragility and bone quality. Osteoporos Int 13:97-104

18. van Dieën JH, Kingma I (2005) Effects of antagonistic co-contraction on differences between electromyography based and optimization based estimates of spinal forces. Ergonomics 48:411-426

19. van Dieën JH, van der Veen A, van Royen BJ, Kingma I (2006) Fatigue failure in shear loading of porcine lumbar spine segments. Spine (Phila Pa 1976) 31:E494-E498

20. van Solinge GB, van der Veen AJ, van Dieën JH, Kingma I, van Royen BJ (2010) Anterior shear strength of the porcine lumbar spine after laminectomy and partial facetectomy. Eur Spine J 19:2130-2136

21. Weinstein JN, Lurie JD, Tosteson TD, Hanscom B, Tosteson AN, Blood EA et al (2007) Surgical versus nonsurgical treatment for lumbar degenerative spondylolisthesis. $\mathrm{N}$ Engl J Med 356:2257-2270 